CASE REPORT

\title{
Respiratory bronchiolitis associated interstitial lung disease (RB-ILD): a case of an acute presentation
}

\author{
D Mavridou, D Laws
}

Thorax 2004;59:910-911. doi: 10.1136/thx.2003.011080

Respiratory bronchiolitis associated interstitial lung disease (RB-ILD) is a recently described clinicopathological entity that occurs almost exclusively in current heavy cigarette smokers. Few cases have been reported in the literature and no studies have been carried out on the effect of treatment, which currently consists of smoking cessation with or without corticosteroids. We report the first case of an acute presentation of histologically proven RB-ILD in a young cigarette smoker whose diagnosis and management proved to be difficult. Smoking cessation alone was found to be inadequate so management was combined with corticosteroid therapy.

$\mathrm{R}$ espiratory bronchiolitis (RB) is a mild inflammatory process observed commonly in asymptomatic cigarette smokers. $^{12}$ The diagnosis ${ }^{34}$ can be based on the combination of (1) clinical evidence of interstitial lung disease; (2) computed tomography (CT) findings of centrilobular nodularity and mild ground glass attenuation; (3) pulmonary function abnormalities; and (4) biopsy specimen showing respiratory bronchiolitis. RB-ILD is the term used to describe the condition in those smokers who become symptomatic secondary to RB. ${ }^{5}$ We report a case of histologically proven RB-ILD in a young cigarette smoker which demonstrates the difficulties in diagnosis and treatment.

\section{CASE REPORT}

A 30 year old woman presented to the thoracic outpatient department complaining of a productive cough with an abnormal chest radiograph showing left upper lobe shadowing. A diagnosis of resolving pneumonia was made and the patient improved spontaneously after smoking cessation. She had a smoking history of 11.25 pack years ( 15 cigarettes per day for 15 years), had no other past medical history of note, and was on no medication. She had no exposure to environmental agents known to cause lung disease.

She represented to hospital 3 months later complaining of increasing breathlessness over the preceding 2 weeks, fevers, sweats, generalised chest tightness, and a non-productive cough despite antibiotic therapy by her GP. She had recommenced smoking in the preceding 10 weeks.

On clinical examination she looked unwell, breathless, and tachypnoeic, and was unable to complete sentences. She was mildly febrile, auscultation of her chest revealed widespread inspiratory and expiratory wheeze, and her peak expiratory flow rate was $160 \mathrm{l} / \mathrm{min}$. Arterial blood gases on air were normal, her white cell count was $20.3 \times 10^{9} / 1$ (neutrophils $18.8 \times 10^{9} / 1$, lymphocytes $0.9 \times 10^{9} /$, eosinophils $0.1 \times 10^{9} / 1$ ), and the electrocardiogram showed sinus tachycardia. The chest radiograph showed interstitial shadowing in both hilar regions consistent with alveolitis. The patient was initially treated with broad spectrum antibiotics and nebulised bronchodilators. A test for HIV following consent, atypical serology, and autoimmune profile were all negative and immunoglobulins were normal; the erythrocyte sedimentation rate was $73 \mathrm{~mm} /$ hour and C-reactive protein was $173 \mathrm{mg} / \mathrm{l}$. Respiratory function tests showed a forced expiratory volume in 1 second $\left(\mathrm{FEV}_{1}\right)$ of $0.98 \mathrm{l} / \mathrm{s} \quad(31.7 \%$ of predicted) and a forced vital capacity (FVC) of $1.61 \mathrm{l}$ (45.4\% of predicted), making an $\mathrm{FEV}_{\mathrm{l}} / \mathrm{FVC}$ ratio of $60.79 \%$ ( $109.3 \%$ of predicted).

A chest CT scan showed perihilar ground glass opacities with no bronchiectasis or nodules (fig 1). The thoracic radiologist suggested a diagnosis of RB-ILD but the differential diagnosis included drug reaction, Pneumocystis carinii pneumonia (PCP), extrinsic allergic alveolitis (EAA), or sarcoidosis. Fibreoptic bronchoscopy showed no endobronchial lesions and transbronchial biopsy specimens were obtained from the lingula. Histological examination showed prominent accumulation of pigment laden macrophages within alveolar spaces with mild interstitial inflammation and no significant fibrosis (fig 2); this was consistent with a diagnosis of RB-ILD. There was no histological evidence of sarcoidosis or EAA. The patient was diagnosed as having RBILD as all other differential causes of her abnormal CT scan and symptoms had been excluded. The patient was commenced on high dose corticosteroids and advised to stop smoking. She was subsequently discharged home as she had clinically improved.

Six weeks later she was reviewed in the outpatient department and improvement continued both clinically and radiologically; the carbon monoxide transfer factor (TLCO) had increased to $83 \%$ of predicted. Prednisolone was tapered

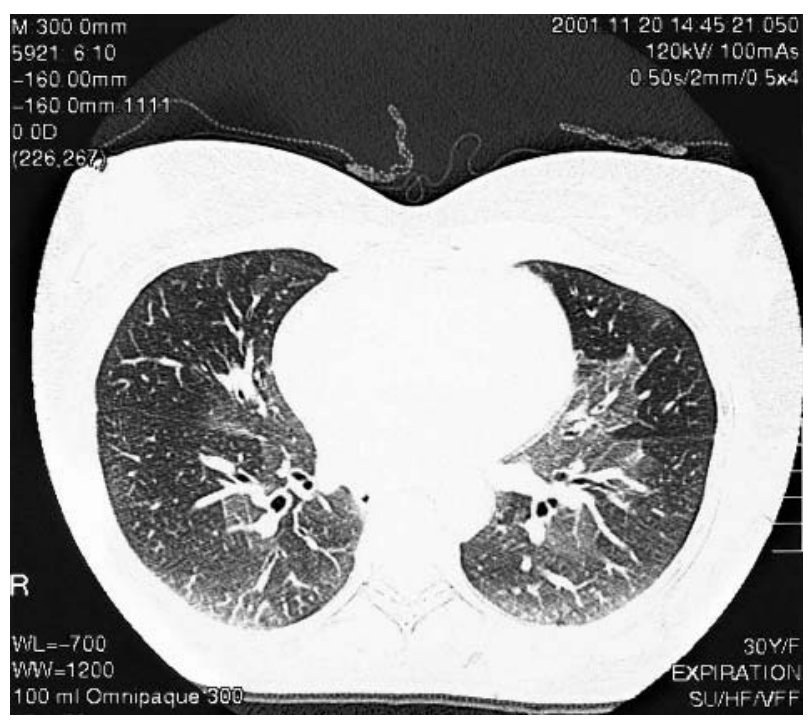

Figure 1 CT scan showing perihilar ground glass opacities. 


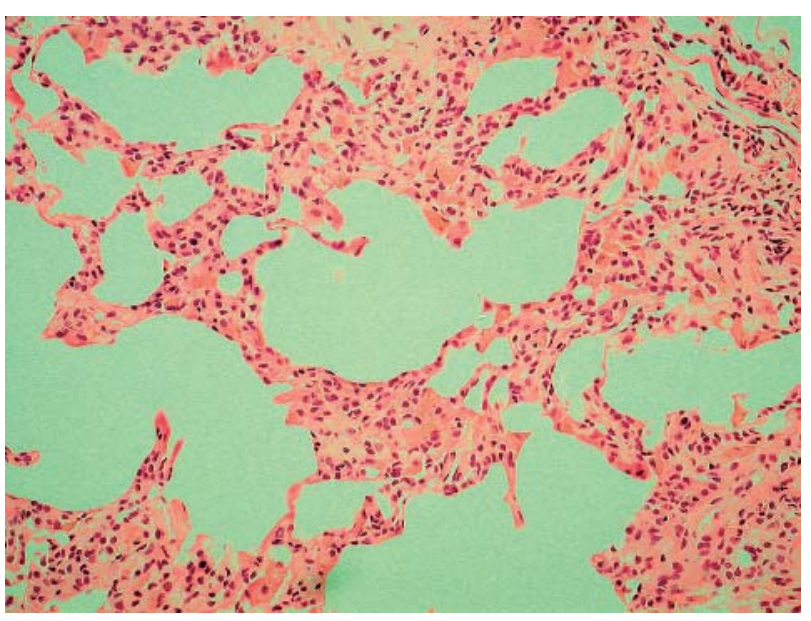

Figure 2 Transbronchial biopsy specimen showing very prominent accumulation of pigment laden macrophages within alveolar spaces with mild interstitial inflammation.

down to $5 \mathrm{mg}$ but the patient began deteriorating clinically with symptoms of cough and breathlessness, despite remaining a non-smoker. The TLCO decreased down to $70 \%$ of predicted and a chest radiograph showed worsening perihilar infiltration. Because of the observed deterioration, the patient was given a further longer course of high dose corticosteroids. Prophylaxis against osteoporosis was also initiated as part of the management. To our knowledge, this has not been previously reported in patients with RB-ILD. The patient's progress is currently being followed in the outpatients department which will continue for a minimum of 2 years following withdrawal of treatment to detect relapse early. The most recent TLCO was $80 \%$ of predicted 12 months after diagnosis and it is hoped that the steroids can be gradually withdrawn without further relapse.

\section{DISCUSSION}

RB-ILD is a recently recognised clinicopathological entity that is seen in current heavy cigarette smokers. Niewoehner et al ${ }^{1}$ studied the lungs of young cigarette smokers and compared them with those of controls. The pathological lesion observed was that of an RB associated with clusters of pigmented macrophages which was rarely seen in non-smokers. Myers et $a l^{6}$ described six patients with clinical, physiological, and radiological evidence of chronic interstitial lung disease in whom open lung biopsies showed only RB. Yousem et al described this clinicopathological syndrome as RB-ILD. Most patients are asymptomatic and present in the fourth or fifth decade of life ${ }^{7}$ with insidious onset of dyspnoea accompanied by mild restriction and reduction in TLCO on respiratory function testing. The chest radiographs are abnormal in 70$80 \%$ of reported cases ${ }^{7}$ and show reticulonodular opacities, typically fine and diffuse or basally predominant. ${ }^{8}$ The most common finding on the high resolution CT scan is areas of ground glass opacity with upper lung zone predominance. ${ }^{4}$
The diagnosis is confirmed by histological examination (preferably open lung or thoracoscopic biopsy), with the most characteristic feature being the accumulation of tan brown macrophages in the intraluminal and peribronchial air spaces. ${ }^{2}$ The prognosis is very good with no deaths reported, and patients improve or stabilise after smoking cessation" with or without corticosteroid treatment. There are no reports or studies regarding the dose or duration of treatment, but this case showed evidence of relapse even without recommencing smoking after reducing the corticosteroids over the course of a few weeks. The decision for a longer duration of treatment was therefore made. Notwithstanding, smoking cessation is very important for the course of the disease, as shown in this case. When the patient first presented at the clinic with "pneumonia" she had stopped smoking for a short period of time as she was unwell. However, when she improved she restarted smoking leading to her deterioration and admission. It is the authors' belief that RB-ILD was the cause of the initial illness at presentation and she showed improvement after smoking cessation alone. Although clinically the need to continue steroids did not follow the usual pattern of RB-ILD, we are confident that this was the final diagnosis. More studies are required to compare the effects of smoking cessation alone and combined with corticosteroid treatment.

\section{Authors' affiliations \\ D Mavridou, D Laws, Thoracic Department, Royal Bournemouth Hospital, Bournemouth, UK}

Correspondence to: Dr D Mavridou, Thoracic Department, Royal Bournemouth Hospital, Castle Lane East, Bournemouth BH7 7DW, UK; despina@doctors.net.uk

Received 4 June 2003

Accepted 14 November 2003

\section{REFERENCES}

1 Niewoehner DE, Kleinerman J, Rice DB, et al. Pathologic changes in the peripheral airways of young cigarette smokers. N Engl J Med 1974:291:755-8

2 Yousem SA, Colby TV, Gaensler EA. Respiratory bronchiolitis-associated interstitial lung disease and its relationship to desquamative interstitial pneumonia. Mayo Clin Proc 1989;64:1373-80.

3 Park JS, Brown KK, Tuder RM, et al. Respiratory bronchiolitis-associated interstitial lung disease: radiologic features with clinical and pathologic correlation. J Comput Assist Tomogr 2002;26:13-20.

4 Holt RS, Schmidt RA, Godwin D, et al. High resolution CT in respiratory bronchiolitis-associated interstitial lung disease. J Comput Assist Tomogr 1993;17:46-50.

5 Hartman TE, Tazelaar HD, Swensen SJ, et al. Cigarette smoking: CT and pathologic findings of associated pulmonary diseases. Radiographics 1997; 17:377-90.

6 Myers JL, Veal CF, Shin MS, et al. Respiratory bronchiolitis causing interstitial lung disease: a clinicopathologic study of six cases. Am Rev Respir Dis 1987; 135:880-4

7 Aubry MC, Wright JL, Myers JL. Review. The pathology of smoking-related lung diseases. Clin Chest Med 2000;21:11-35.

8 Hansell DM. Diseases of the airways. In: Armstrong P, Wilson A, Dee P Hansell DM, eds. Images of diseases of the chest.Harcourt Publishers, 2001:893-947.

9 Nagai S, Hoshino Y, Hayashi M, et al. Review. Smoking-related interstitial lung diseases. Curr Opin Pulm Med 2000;6:415-9. 